\title{
An Analysis on the Development of Dong Nationality Settlement from Ecological Perspective
}

\author{
Yanmin Liang ${ }^{1, a^{*}}$ and Zhimeng Huang ${ }^{2, b}$ \\ ${ }^{1}$ School of Arts, Guilin University of Technology, 541004, Guilin, Guangxi, China \\ ${ }^{2}$ Guilin Institute of Architectural Design,541000,Guilin, Guangxi, China \\ aliangyanmin2012@163.com, ${ }^{\mathrm{b}} 1831123770 @ q q . c o m$
}

Key words: Village; Settlement; Space; Ecology

\begin{abstract}
The traditional concept about original ecological culture can be reflected largely by the unique settlement culture of Dong nationality and their behavioral habits. Actually in Dong nationality villages, the site selection and the spatial construction have also shown their unique cultural and ecological landscape. In this paper, through the analysis on the spatial pattern of Dong nationality settlement in North Guangxi, we make an attempt to find out the spatial characteristics of the construction and the components of the village. Also through the study on the cultural crisis faced by the Dong nationality settlement, we give some suggestion in this paper regarding the principle and the measures taken to protect and utilize the settlement space of Dong nationality.
\end{abstract}

\section{Introduction}

In the northern area of Guangxi of China, various ethnic minorities are living here, such as Miao, Yao, Dong and Zhuang nationalities. For different national minorities, they have different traditional culture that conforms to their own ethnic characteristics. As to Dong nationality, all of the Dong people have been living in groups according to the family name. In normal cases, if people are living in the same village, they shall have the same family name. Villages are separated from each other according to the different drum towers. In fact, the living mode of every village has been affected by the local living custom and the national culture.

\section{The Impact of Natural Environment on the Settlement Pattern of Dong Nationality}

In the inhabited area of Dong nationality in the mountainous area of north Guangxi, village is not just an architectural settlement. Instead, it's connected closely with the traditional cultural landscape and the relevant natural environment. In fact, limited by the natural environment, villages might be similar or different in the forms.

Throughout the whole history of Dong nationality, Dong people have been living in groups. However they do also abide by some principles to choose the site of village. For example, if this place is suitable for habitation, or if it's near the rivers and mountains. The reason that Dong people have a strong sense of ethnic identity and group consciousness is due to their residential custom, which is that a family group or several family groups have been living together. Actually living beside the mountains and rivers has not only conformed to the traditional culture of Dong people, but also catered for the breeding and survival of Dong nationality. With a long history of sediment, the culture of Dong nationality continues to inherit the features of the original ethnic culture. This can be reflected through the cultural loading-bearing and continuity. For example: The tradition of the Baiyue ethnic groups, who had "lived by streams, in valleys and bamboo forests instead of cities and towns", or "lived along mountains and rivers" has been inherited [1].In fact, since rice farming has been the main measure for Dong people to support their families, then Dong nationality cannot live in a place without water. Also this place must be surrounded by mountains to provide the necessary support for Dong people, who can thus plant trees in the forest. Actually all of the trees will provide a great deal of bamboo and timber for their building of houses. Moreover, land reclamation for terraced fields can also be done on the mountains. 
The site selection in the inhabited area of Dong nationality in north Guangxi has reflected the close relationship with the natural geographical environment. Roughly the terrain can be classified into the following types.

The Type of Village at the Mountain Foot and Riverside. Such a type of village located near the river with hills on the back is very common in the inhabited area of Dong nationality, accounting for $80 \%$ of the total Dong villages. It's a typical type of village that focuses on the landscape configuration. Generally, all of such villages are located before the mountains but after the stream or river. [2] This is one of the most common types of Dong nationality village.( refer with: Fig. 1)

The Type of Village in the Plain Region and Countryside. In general, this kind of village is located in a place with mountains and river. However due to a series of reasons such as river blocking or cutoff by yellow sand, there emerges in the river channel a flat area, which exactly is the so-called flatland. As a matter of fact [3], around 15\% of the total Dong nationality villages are located in the middle or the edge of a flatland such as Chengyang Eight Stockade in Sanjiang Country of Guangxi Province. The ups and downs of the terrain make the road wind into the villages with an uneven surface. As all of the buildings are constructed according to the terrain in a well-arranged layout at different heights, it shows a natural and wonderful outline .

The Type of Village at the Mountain Pass on A Hillside. When the Dong nationality village is built on a mountain pass according to the different terrains, it can be classified into the so-called mountain pass village on a hillside. However not so many Dong people have adopted such a mode to build their village, as this type of village has always been built on a hillside with the adoption of this site selection mode. Of course, there is a premise that water source must be available around the place. In fact, it looks very magnificent at a distance when the buildings are constructed on the hillside tier upon tier according to the mountain terrain. (refer with: Fig. 2)

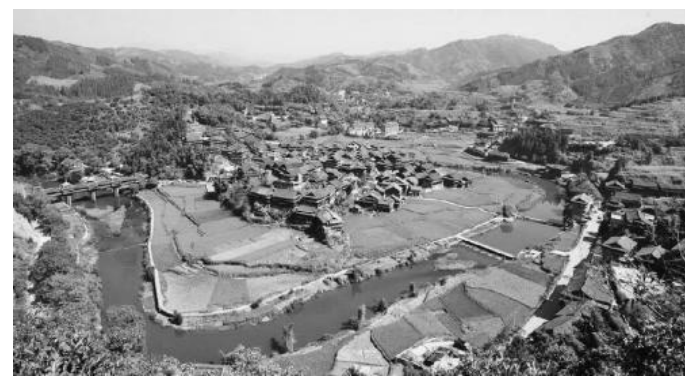

Figure 1.

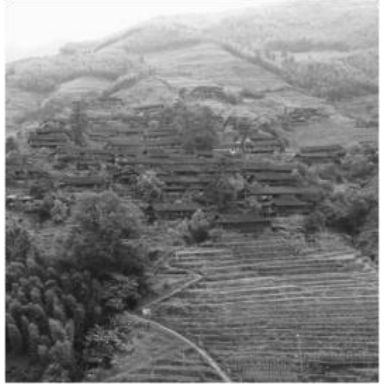

Figure 2.

Although there is certain difference in all of these three site selection modes, the common character is also very clear. Firstly, site selection is inextricably linked to water in all of these modes. Secondly, through the skillful utilization and systematization of the relationship between the village and the mountain, basically all of the villages have been built according to the mountain terrain. In fact, such a flexible and skillful application based on the topography will combine human with nature perfectly. Also with the expansion of the village, a composite form of village will turn up. Then it's clear that the external morphology of the village is connected closely with the way that people treat the natural environment and their living style.

\section{The Creation of Settlement Space for Dong Nationality}

The various development stages of Dong nationality village have been determined jointly by various factors, such as the traditional culture, the social production and the geographical position etc. The most basic feature of Dong nationality village is spatiality. From the perspective of spatial construction, basically all of the villages are of centripetal type.

As a spatial form of settlement for the survival of Dong people, Dong nationality village has reflected the multiple requirements of Dong people in terms of their thoughts and ideology. With 
the tactful application of the physical technology based on their material life, Dong people have managed to create their villages [4].The spatial construction of Dong nationality village from the aspect of boundaries, nodes, roads and landmarks enables the Dong people to establish a relationship with the natural environment. In this way, Dong people will have a sense of security to better experience the connotation of the village from both depth and strength.

Boundaries. Boundary marks the maximum range of the place where people in the same community live together [5], For most of the villages in the inhabited area of Dong nationality, generally the various linear or vertical landscapes such as the river that flows around the village, the hillside and the mountain pass etc. are all considered as part of or the whole boundary line of the village. If such a natural boundary line is not available, some specific boundaries, such as the shelter bridge or the village gate will be adopted. All of these specific boundaries constitute the symbolic border of the village.

Dong nationality thinks highly of the boundary. Even they value these boundaries more than the construction of the village itself. Actually it's of great symbolic significance when the border of the whole village has been constituted by the natural boundaries and the specific physical boundaries. Due to the common cognitive basis, all of the Dong people might mentally gain a sense of security and satisfaction from the border. .Actually with the presence of border, village will be more spatial. Also it enables people to outline an area that they are more confident with in the complex natural environment.

Nodes. In a Dong nationality village, there might be some nodes for special purposes, such as the wellbay and the small square etc. Although there are many narrow and linear streets in the village, the presence of these nodes will break the narrow space in the streets, which won't look as singular as before. Also it makes the whole village give a sense of depth. Actually the spatial construction of the village based on the nodes located in the center of the village is the main characteristic of Dong nationality village.

As a focus to keep the village in order, the central space of the village is the driving source for Dong people to live together. It makes people who have lived in the enclosed boundaries have a sense of security, direction and identity. For the center of a Dong nationality village, sometimes it's dimensional with spatial character, but sometimes it's tangible as a landmark. As long as the village center is available, it will facilitate people to better understand the whole layout and the order of the village. Also it will make every village become identifiable.

Generally, drum tower is considered as the central space of a Dong nationality village. This is mainly because of its special social and functional significance and the peculiar morphological characteristics of the drum tower. Not to mention that Dong people always psychologically have a sense of identity with it, even they worship the drum tower. Therefore in a Dong nationality village, half of the village is centered by the drum tower [4] with the supplementation of some other elements. Sometimes the drum tower is located in the geographic center of the village, but sometimes it might be in the other place. However the site selection won't affect its function as a spatial center. ( refer with: Fig. 3)

Roads and Streets. In a Dong nationality village, road building always starts from the construction of a house. Then, road will be built after an analysis has been made on where most of people will walk on. Under such a circumstance, roads in the villages are always characterized by randomness and give forth an odor of simplicity. It has been called as Banbian Street, when the street runs beneath various buildings. With the construction of such a street, roads will go straightway unblocked within the village, and the building lot will not be affected as well. [6] As one of the important factors to connect the various nodes in the village, streets act as a framework to constitute the village, while roads lead people how to move. Actually streets are the inner space enclosed by the folk houses and the other buildings that have been densely constructed in the village. (refer with: Fig. 4). 


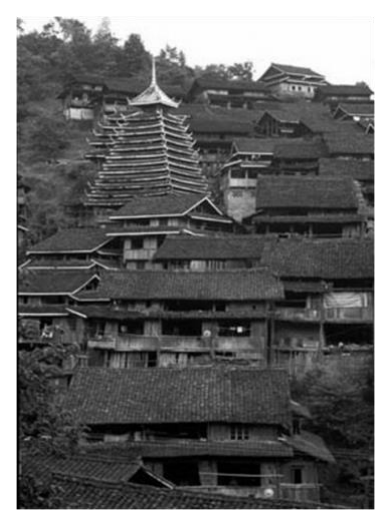

Figure 3.

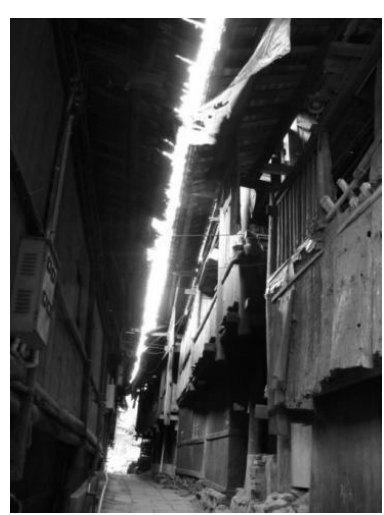

Figure 4.

\section{Conflict Faced By Dong Nationality in the Traditional Settlements}

In the process of urbanization, many of the Dong villages are not as enclosed as those in the past. Actually, with the introduction of more and more external resources, the life of the Dong people has been changed greatly. Now Dong people are facing a series of reforms ranging from the concept of value, the family structure and the behavioral pattern to the village organization.

With the rapid development of the modernization process, now village urbanization has become an inevitability. The original traditional mode of construction, the materials and the old living mode cannot completely cater for the current requirement any more. Since all of these contradictions and conflicts are unavoidable, then we shall make every effort to protect and correct timely the present settlement system to make it conform to the development of the whole society and the times.

\section{Protection and Utilization of Dong Nationality Village}

Texture Coordination. Texture has been an important factor to constitute the landscape vision for Dong nationality settlements[7]. The "simulation" of natural textures refers to the formation of such spatial fabrics that are similar to the natural environment when the villages have been built in a layout according to the mountain topography or along the rivers. Also all of the buildings in the village have been arranged tier upon tier based on the isohypse line or in a line along the river.

In the mountainous settlement environment of northern Guangxi, generally all of the buildings in the villages have been constructed with bricks and timber, and made of cedarwood. As this kind of material always turns gray due to the weathering, then it looks quite harmonious with the vegetation texture. From the three dimensional perspective, the whole Dong village is highly uniform in the gray color in terms of the outer spatial form. Then the integration with the natural environment will demonstrate a beautiful countryside mountain landscape [8]. Therefore, during the design and planning of the village, we shall try to keep the whole building in an ancient style, and continue to maintain the original ecological structure of the building with the adoption of cedarwood. Moreover we shall try to keep the trees green, and plant as many trees as possible along the streets in the village.

Landscape Spatial Planning. Generally, the landscape of the Dong village has been characterized by a unique feature. Instead of in a plane layout, the buildings in the village are always spatial in a hierarchical structure. As there are mountains and rivers around the village in addition to the availability of natural vegetation, the village always shows the natural beauty that is alternately dark and bright, demonstrating a rather beautiful village landscape. Hence in the planning, design and construction process, the planning of the city morphology might focus on an area, where the pedestrian street can be located in the middle of the district. Also try to take the series changes in the landscape space into account. [9]

Respect for the Traditional Geomancy and Secure Water Circulation in the Settlement Environment. Dong village that is built near the mountain and by the river has reflected really the traditional cultural characteristics of Dong nationality in the settlement. During the construction of 
village, firstly, the availability of water source around the environment must be taken into account. As the root for the construction, water is something indispensable to connect streets, shelter bridge, drum tower and folk houses. Just like the majority of people in Han nationality, Dong people also believe that water can bring fortune. Hence in order to secure a plentiful water supply to the village, make sure to take every measure to ensure smooth water circulation in the village. Also in order to maintain favorable hydrological conditions and micro-climate in the settlement environment, it's necessary to make a reasonable integration of the existing resources according to the present housing condition and based on the current science and technology. [10] On the other hand, it's necessary to accelerate the introduction of stream to ensure the natural circulation of water flow.

\section{Conclusion}

Original ecological environment has been maintained in Dong village among the various settlements in the north of Guangxi Province. It reaches a harmonious unification of site selection and surrounding environment with a natural integration of buildings and environment. As a matter of fact, the protection and utilization of the settlement culture of Dong nationality will facilitate us to inherit and develop the outstanding regional ethnic culture.

\section{Acknowledgements}

This paper has been one of the staged achievements in the philosophical and social project launched in Guangxi Province under the title of "Study on the protection and development of the settlement pattern of Dong nationality in Guangxi Province from the perspective of ecology" (Project Number:13FMZ010).

\section{References}

[1] Li Jianhua. The cultural Interpretation of Southwest Settlement Patterns [D]. Chongqing University: 2011

[2] Mao Guohui. The Dong nationality's traditional Ganlan-style residence climate adaptation and functional integration study [D]. Hunan University:2012

[3] Zhang Xiucheng, Xu Shanshan, Tan Miaomeng. A Brief Analysis on the limitation in the study of architectural culture of national minority-An instance of Dong Minority in southwest[J]. Journal of Beijing University of Civil Engineering and Architecture, 2013, (1):57-60,104

[4] Chen Hongxiang. Study on the constructing technique and culture of Dongs' Drum Tower in the southeast of Guizhou Province [D]. Chongqing University:2012

[5] (Japan) By Hiroshi Hara, Translated by Yu Tian, Liu Shumei. Introduction of 100 global settlements[M]. Beijing: China Building Industry Press, 2003

[6] Fan Junfang, Xiong Xingyao. The Interpretation of the Spatial Structures of Dang Villages[J]. Chinese Landscape Architecture, 2010,(7):76-79

[7] Zhu Jiashun. Research for spaceform of Dong village in Qiandongnan [D]. Southwest Jiaotong University:2011

[8] Dai Yiming. The main points of planning and construction in hilly areas [J]. Urban construction Magazine Press, 2011, (32):98

[9] (USA) By Lan Lennox McHarg, translated by Rui Jingwei. Design with Nature [M]. Tianjin University press

[10] Zhou Bo, Wang Bo, Zhou Zhenlun. Footfalls of multiculture in depths of a small winding street- traditional village and buildings in southeast mountain area of Guizhou Province [J]. Industrial Construction, 2005, (12): 27-28, 46 